\title{
EXISTENCE AND UNIQUENESS THEOREMS FOR RIEMANN PROBLEMS
}

\author{
BY
}

\section{TAI-PING LIU}

ABSTRACT. In [2] the author proposed the entropy condition (E) and solved the Riemann problem for general $2 \times 2$ conservation laws $u_{t}+f(u, v)_{x}$ $=0, v_{t}+g(u, v)_{x}=0$, under the assumptions that the system is hyperbolic, and $f_{u} \geqslant 0$ and $g_{v}<0$. The purpose of this paper is to extend the above results to a much wider class of $2 \times 2$ conservation laws. Instead of assuming that $f_{u}$ $>0$ and $g_{v}<0$, we assume that the characteristic speed is not equal to the shock speed of different family. This assumption is motivated by the works of Lax [1] and Smoller [4].

We consider the $2 \times 2$ conservation laws

$$
\begin{aligned}
& u_{t}+f(u, v)_{x}=0, \\
& v_{t}+g(u, v)_{x}=0,-\infty<x<\infty, \quad t \geqslant 0,
\end{aligned}
$$

where $(u, v)=(u, v)(x, t)$ and $f, g \in C^{2}(U)$ for some open set $U$ in $\mathbf{R}^{2}$. We are interested in the Riemann problem for (1), that is, the Cauchy problem (1) with initial data

$$
(u(x, 0), v(x, 0)) \equiv\left(u_{0}(x), v_{0}(x)\right)= \begin{cases}\left(u_{l}, v_{l}\right) & \text { for } x<0 \\ \left(u_{r}, v_{r}\right) & \text { for } x>0\end{cases}
$$

where $\left(u_{l}, v_{l}\right)$ and $\left(u_{r}, v_{r}\right)$ are arbitrary constants in $U$.

We assume that

$$
f_{v}<0, \quad g_{u}<0
$$

so that (1) is strictly hyperbolic, that is, $d(f, g)$ has real and distinct eigenvalues $\lambda_{1}<\lambda_{2}$. Let $r_{i}$ be right eigenvectors corresponding to $\lambda, i=1,2$. These can be taken of the form $r_{1}=\left(1, a_{1}\right)^{t}, r_{2}=\left(1, a_{2}\right)^{t}$. It can be shown that (3) implies

$$
a_{1}<0<a_{1}
$$

Since the solution to (1) is usually discontinuous, we seek the weak solutions to (1) and (2).

Definition 1. The bounded measurable function $(u, v)$ is said to be a weak solution to (1), (2) if

Received by the editors June 24, 1974 and, in revised form, September 12, 1974. AMS (MOS) subject classifications (1970). Primary 35L65, 35L25.

Key words and phrases. Conservation laws, shocks, rarefaction waves, contact discontinuities, Lax shock inequalities (L), entropy condition (E). 


$$
\begin{aligned}
& \iint_{t \geqslant 0}\left[u \phi_{t}+f(u, v) \phi_{x}\right] d x d t+\int_{t=0} u_{0} \phi d x=0, \\
& \iint_{t \geqslant 0}\left[v \phi_{t}+g(u, v) \phi_{x}\right] d x d t+\int_{t=0} v_{0} \phi d x=0 .
\end{aligned}
$$

for all functions $\phi \in C_{0}^{\infty}(R \times(0, \infty))$.

From (5) it follows that if a weak solution $(u, v)$ is discontinuous along $x=x(t)$, then the following Hugoniot condition is satisfied.

$$
\frac{f\left(u_{+}, v_{+}\right)-f\left(u_{-}, v_{-}\right)}{u_{+}-u_{-}}=\frac{g\left(u_{+}, v_{+}\right)-g\left(u_{-}, v_{-}\right)}{v_{+}-v_{-}}=s
$$

where $\left(u_{+}, v_{+}\right)=(u, v)(x+0, t),\left(u_{-}, v_{-}\right)=(u, v)(x-0, t)$ and $s=\dot{x}(t)$.

Through any point $\left(u_{0}, v_{0}\right)$ in $U$, we define the shock set to be the set

$$
\left.\begin{array}{rl}
S\left(u_{0}, v_{0}\right)=\{(u, v) \in U \mid & \frac{f(u, v)-f\left(u_{0}, v_{0}\right)}{u-u_{0}} \\
& =\frac{g(u, v)-g\left(u_{0}, v_{0}\right)}{v-v_{0}}=\sigma\left(u, v ; u_{0}, v_{0}\right)
\end{array}\right\}
$$

where $\sigma\left(u, v ; u_{0}, v_{0}\right)$ is the shock speed. The Hugoniot condition $(\mathrm{H})$ says that $\left(u_{+}, v_{+}\right) \in S\left(u_{-}, v_{-}\right)$and $s=\sigma\left(u_{+}, v_{+} ; u_{-}, v_{-}\right)$. Condition (3) implies that if $u=u_{0}$ or $v=v_{0}$, then $(u, v)$ is not in $S\left(u_{0}, v_{0}\right)-\left\{\left(u_{0}, v_{0}\right)\right\}$. Hereafter, we assume that for any $\left(u_{0}, v_{0}\right)$ in $U$,

$$
\begin{aligned}
& \text { the shock set } S\left(u_{0}, v_{0}\right) \text { consists of two } \\
& \text { curves } S_{1}\left(u_{0}, v_{0}\right) \text { and } S_{2}\left(u_{0}, v_{0}\right) \text { such } \\
& \text { that for any }(u, v) \text { on } S_{1}\left(u_{0}, v_{0}\right) \text {, } \\
& \left(u, v ; u_{0}, v_{0}\right)<\lambda_{2}(u, v) \text { and for any } \\
& (u, v) \text { on } S_{2}\left(u_{0}, v_{0}\right), \sigma\left(u_{0}, v_{0} ; u, v\right)>\lambda_{1}(u, v) \text {. }
\end{aligned}
$$

In [1], Lax proved that $S_{i}\left(u_{0}, v_{0}\right)$ is tangent to $r_{i}$ at $\left(u_{0}, v_{0}\right)$. Therefore we can write $S_{i}=S_{i}^{+} \cup S_{i}^{-}, i=1,2$, such that $S_{1}^{+}\left(u_{0}, v_{0}\right) \subset \mathrm{I}\left(u_{0}, v_{0}\right)$, $S_{1}^{-}\left(u_{0}, v_{0}\right) \subset \operatorname{III}\left(u_{0}, v_{0}\right), S_{2}^{+}\left(u_{0}, v_{0}\right) \subset \operatorname{IV}\left(u_{0}, v_{0}\right)$ and $S_{2}^{-}\left(u_{0}, v_{0}\right) \in \operatorname{II}\left(u_{0}, v_{0}\right)$ (cf. Figure 1), where $\mathrm{I}\left(u_{0}, v_{0}\right)=\left\{(u, v) \in U \mid u \geqslant u_{0}, v \geqslant v_{0}\right\}$, etc.

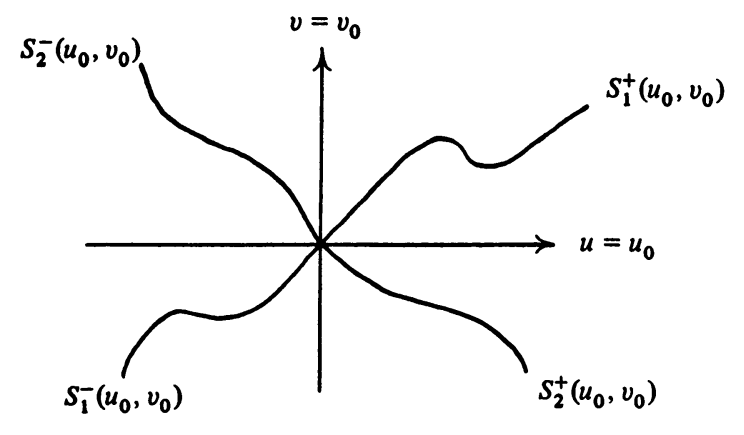

FIGURE 1 
Let $h_{i}=h_{i}\left(u_{0}, v_{0} ; u, v\right)$ be a nonzero smooth tangent to $S_{i}\left(u_{0}, v_{0}\right)$ at $(u, v)$ such that $h_{i}\left(u_{0}, v_{0} ; u_{0}, v_{0}\right)=r_{i}\left(u_{0}, v_{0}\right), i=1,2$. Let $R_{i}\left(u_{0}, v_{0}\right)$ be the integral curve of $r_{i}$ through $\left(u_{0}, v_{0}\right), i=1,2$. Denote by $d / d \mu_{i}$ and $d / d v_{i}$ the directional derivatives along $S_{i}$ and $R_{i}$, respectively, i.e.

$$
d / d \mu_{i}=h_{i} \cdot \nabla \quad \text { and } \quad d / d \nu_{i}=r_{i} \cdot \nabla
$$

It is known that certain elementary weak solutions called $i$-rarefaction waves and $i$-shock waves can be defined along $R_{i}$ and $S_{i}$ curves (see for example [1]).

Lemma 1. Assume that (3) and (6) hold. Set $h_{i}\left(u_{0}, v_{0} ; u, v\right)=$ $\sum_{j=1}^{2} a_{i j} r_{j}(u, v)$. Then $a_{11}>0$ and $a_{22}>0$.

THEOREM 1. Assume that (3) and (6) hold. Then for $(u, v) \in S_{i}^{+}\left(u_{0}, v_{0}\right)$, we have

(i) $d \sigma / d \mu_{i}>0$ if and only if $\sigma<\lambda_{i}$ at $(u, v)$,

(ii) $d \sigma / d \mu_{i}<0$ if and only if $\sigma>\lambda_{i}$ at $(u, v)$; and for $(u, v) \in S_{i}\left(u_{0}, v_{0}\right)$, we have

(iii) $d \sigma / d \mu_{i}>0$ if and only if $\sigma>\lambda_{i}$ at $(u, v)$,

(iv) $d \sigma / d \mu_{i}<0$ if and only if $\sigma<\lambda_{i}$ at $(u, v)$.

Lemma 2. Assume that (3) and (6) hold. Let $\left(u_{1}, v_{1}\right)$ and $\left(u_{2}, v_{2}\right)$ be points on $S_{i}\left(u_{0}, v_{0}\right), i=1$ or 2 , such that $\sigma\left(u_{1}, v_{1}, u_{0}, v_{0}\right)=\sigma\left(u_{2}, v_{2} ; u_{0}, v_{0}\right)$. Then $\left(u_{1}, v_{1}\right) \in S_{i}\left(u_{2}, v_{2}\right)$ and $\sigma\left(u_{1}, v_{1} ; u_{2}, v_{2}\right)=\sigma\left(u_{1}, v_{1} ; u_{0}, v_{0}\right)$.

Theorem 1 and Lemmas 1 and 2 were proved in [3]. Our next theorem is important in solving the Riemann problem.

Theorem 2. Suppose that (3) and (6) hold. Assume that $\left(u_{1}, v_{1}\right) \in$ $S_{1}\left(u_{0}, v_{0}\right)$ and $\left(u_{2}, v_{2}\right) \in S_{2}\left(u_{0}, v_{0}\right)$. Then $\sigma\left(u_{1}, v_{1} ; u_{0}, v_{0}\right)<\sigma\left(u_{2}, v_{2} ; u_{0}, v_{0}\right)$.

Proof. We only prove the theorem when $u_{1}>u_{0}$ and $u_{2}>u_{0}$. The other cases are proved similarly.

Suppose, on the contrary, $\sigma\left(u_{1}, v_{1} ; u_{0}, v_{0}\right) \geqslant \sigma\left(u_{2}, v_{2} ; u_{0}, v_{0}\right)$. Since, by (7), $\sigma\left(u_{2}, v_{2} ; u_{0}, v_{0}\right)>\lambda_{1}\left(u_{0}, v_{0}\right)$, there exists $\left(u_{3}, v_{3}\right)$ on $S_{1}^{+}\left(u_{0}, v_{0}\right)$ between $\left(u_{0}, v_{0}\right)$ and $\left(u_{1}, v_{1}\right)$ such that $\sigma\left(u_{0}, v_{0} ; u_{2}, v_{2}\right)=\sigma\left(u_{0}, v_{0} ; u_{3}, v_{3}\right)$. It follows that $\left(u_{2}, v_{2}\right) \in S\left(u_{3}, v_{3}\right),\left(u_{3}, v_{3}\right) \in S\left(u_{2}, v_{2}\right)$ and $\sigma\left(u_{3}, v_{3} ; u_{2}, v_{2}\right)=$ $\sigma\left(u_{0}, v_{0} ; u_{2}, v_{2}\right)=\sigma\left(u_{0}, v_{0} ; u_{3}, v_{3}\right)$.

If $u_{0}<u_{3}<u_{2}$, then $\left(u_{3}, v_{3}\right) \in S_{1}^{-}\left(u_{3}, v_{3}\right)$. Therefore by Lemma 2, $\left(u_{3}, v_{3}\right) \in S_{2}\left(u_{0}, v_{0}\right)$ which is a contradiction.

If $u_{0}<u_{2}<u_{3}$, then $\left(u_{0}, v_{0}\right) \in S_{1}^{-}\left(u_{3}, v_{3}\right)$ and $\left(u_{2}, v_{2}\right) \in S_{2}^{-}\left(u_{2}, v_{2}\right)$. Again by Lemma $2,\left(u_{2} ; v_{2}\right) \in S_{1}\left(u_{0}, v_{0}\right)$ which is a contradiction.

This completes the proof of the theorem. Q.E.D.

For simplicity, we make the following assumption: 
The intersection of any $R_{i}$ curve with the set $V_{i} \equiv\left\{(u, v) \mid d \lambda_{i}\left(r_{i}\right)=0\right\}$ does not have any accumulation point.

As was shown in [2], the crucial step in proving the existence and uniqueness theorems for the Riemann problem is to first establish the analogous theorems for $i$-waves, $i=1,2$. For this, we construct a curve $\alpha_{i}\left(u_{0}, v_{0}\right)$ such that $\left(u_{0}, v_{0}\right)$ is connected to any $(u, v)$ on $\alpha_{i}\left(u_{0}, v_{0}\right)$ on the right by $i$-waves. We now describe briefly the construction of the curves $\alpha_{i}\left(u_{0}, v_{0}\right)$.

Suppose $d \lambda_{i}\left(r_{i}\right)<0$ at $\left(u_{0}, v_{0}\right)$, then the first segment of $\alpha_{i}\left(u_{0}, v_{0}\right)$ is $S_{i}^{+}\left(u_{0}, v_{0}\right)$ and the solution of the Riemann problem $\left\{\left(u_{0}, v_{0}\right) ;(u, v)\right\},(u, v) \in$ $S_{i}^{+}\left(u_{0}, v_{0}\right)$ and $\left|u-u_{0}\right|$ small, is an $i$-shock. As $(u, v)$ moves further away from $\left(u_{0}, v_{0}\right)$ along $S_{i}^{+}\left(u_{0}, v_{0}\right)$, we may have $\sigma\left(u_{1}, v_{1} ; u_{0}, v_{0}\right)=\lambda_{i}\left(u_{1}, v_{1}\right)$ at some $\left(u_{1}, v_{1}\right) \in S_{i}^{+}\left(u_{0}, v_{0}\right)$. The curve $\alpha_{i}\left(u_{0}, v_{0}\right)$ is then continued from $\left(u_{1}, v_{1}\right)$ by the rarefaction curve $R_{i}\left(u_{1}, v_{1}\right)$, so that the solution is a shock wave connecting $\left(u_{0}, v_{0}\right)$ to $\left(u_{1}, v_{1}\right)$ followed by a rarefaction wave connecting $\left(u_{1}, v_{1}\right)$ to $(u, v)$ on $R_{i}\left(u_{1}, v_{1}\right)$. When $R_{i}\left(u_{1}, v_{1}\right)$ first leaves the region $\left\{(u, v) \mid d \lambda_{i}\left(r_{i}\right)>0\right.$ at $(u, v)\}$ at $\left(u_{2}, v_{2}\right)$, we continue $\alpha_{i}\left(u_{0}, v_{0}\right)$ from $\left(u_{2}, v_{2}\right)$ with a mixed curve $\gamma^{*}$ corresponding to $\gamma$. Here $\gamma$ is the $R_{i}$ curve between $\left(u_{1}, v_{1}\right)$ and $\left(u_{2}, v_{2}\right)$, and $\gamma^{*}$ is defined as follows:

$(u, v) \in \gamma^{*}$ if and only if there is $\left(u^{*}, v^{*}\right) \in \gamma$ such that $(u, v)$ is the first point on $S_{i}^{+}\left(u^{*}, v^{*}\right)$ with $\sigma\left(u, v ; u^{*}, v^{*}\right)=\lambda_{i}\left(u^{*}, v^{*}\right)$.

For $(u, v) \in \gamma^{*}$ with corresponding $\left(u^{*}, v^{*}\right) \in \gamma$, we solve the Riemann problem $\left\{\left(u_{0}, v_{0}\right) ;(u, v)\right\}$ by connecting $\left(u_{0}, v_{0}\right)$ to $\left(u_{1}, v_{1}\right)$ by an $i$-shock, $\left(u_{1}, v_{1}\right)$ to $\left(u^{*}, v^{*}\right)$ by an $i$-rarefaction wave and $\left(u^{*}, v^{*}\right)$ to $(u, v)$ by an $i$-shock. The $i$-shock $\left\{\left(u^{*}, v^{*}\right) ;(u, v)\right\}$ has the property that the shock speed $\sigma$ coincides with $\lambda$ on either side of the shock, we call such continuity a contact discontinuity. Suppose there is a point $\left(u_{2}, v_{2}\right)$ on $\gamma^{*}$ such that $\sigma\left(u_{2}, v_{2} ; u_{2}^{*}, v_{2}^{*}\right)=$ $\lambda_{i}\left(u_{2}^{*}, v_{2}^{*}\right)=\lambda_{i}\left(u_{2}, v_{2}\right)$. We then continue $\alpha_{i}\left(u_{0}, v_{0}\right)$ from $\left(u_{2}, v_{2}\right)$ by $R_{i}\left(u_{2}, v_{2}\right)$. Continue these processes so that $\alpha_{i}\left(u_{0}, v_{0}\right)$ is composed of shock, rarefaction and mixed curves. It is shown that the mixed curve $\gamma^{*}$ is tangent to $S_{2}^{+}\left(u^{*}, v^{*}\right)$ at $(u, v)$.

The solution of the Riemann problem $\left\{\left(u_{0}, v_{0}\right),(u, v)\right\},(u, v) \in \alpha_{i}\left(u_{0}, v_{0}\right)$, satisfies the following extended entropy condition $(E)$ across any discontinuity $\left(u_{-}, v_{-}\right)$and $\left(u_{+}, v_{+}\right)$:

$$
\begin{aligned}
& \sigma\left(u, v ; u_{-}, v_{-}\right) \geqslant \sigma\left(u_{+}, v_{+} ; u_{-}, v_{-}\right) \text {for every } \\
& (u, v) \in S_{i}\left(u_{-}, v_{-}\right) \text {between }\left(u_{-}, v_{-}\right) \text {and } \\
& \left(u_{+}, v_{+}\right) .
\end{aligned}
$$

It can be shown that condition (E) is equivalent to Lax's shock inequalities [2] when (1) is genuinely nonlinear. 
THEOREM 3. Suppose that (3), (6) and (7) hold. Then through each point $\left(u_{0}, v_{0}\right)$ in $U$, there exist smooth curves $\alpha_{i}\left(u_{0}, v_{0}\right)$ and $\beta_{i}\left(u_{0}, v_{0}\right), i=1,2$, such that for any $(u, v)$ on $\alpha_{i}\left(u_{0}, v_{0}\right)\left(\beta_{i}\left(u_{0}, v_{0}\right)\right),\left(u_{0}, v_{0}\right)$ can be connected to $(u, v)$ on the right (left) by i-shocks, $i$-rarefaction waves and $i$-contact discontinuities such that condition $(\mathrm{E})$ is satisfied across any discontinuity. Conversely, if $(u, v)$ is any point in $U$ which can be connected to $\left(u_{0}, v_{0}\right)$ on the left (right) by $i$ waves satisfying condition (E), then $(u, v) \in \alpha_{i}\left(u_{0}, v_{0}\right)\left(\in \beta_{i}\left(u_{0}, v_{0}\right)\right), i=1,2$, and the solution has a unique form.

The proof of Theorem 3 is rather complicated. However, using Theorem 1, we can prove Theorem 3 by essentially the same techniques used in the proof of Theorems 2.1 and 3.1 in [2]. We omit the proof.

THEOREM 4. Suppose that there exists $\left(u_{m}, v_{m}\right)$ such that $\left(u_{m}, v_{m}\right) \in$ $\alpha_{1}\left(u_{l}, v_{l}\right) \cap \beta_{2}\left(u_{r}, v_{r}\right)$. Then the Riemann problem $\left\{\left(u_{l}, v_{l}\right) ;\left(u_{r}, v_{r}\right)\right\}$ can be solved by connecting $\left(u_{l}, v_{l}\right)$ to $\left(u_{m}, v_{m}\right)$ by 1-waves and $\left(u_{m}, v_{m}\right)$ to $\left(u_{r}, v_{r}\right)$ by 2-waves such that condition $(\mathrm{E})$ is satisfied across any discontinuity.

Proof. The theorem is an immediate consequence of Theorem 3. We have only to show that the 1-waves connecting $\left(u_{l}, v_{l}\right)$ and $\left(u_{m}, v_{m}\right)$, and the 2-waves connecting $\left(u_{m}, v_{m}\right)$ and $\left(u_{r}, v_{r}\right)$ do not overlap and are separated by the constant $\left(u_{m}, v_{m}\right)$. Indeed by (6) and Theorem 2 we know that the 1 -waves and 2-waves do not overlap in the $x-t$ plane. Q.E.D.

When condition (6) fails, and so does Theorem 2, then 1-waves may overlap 2-waves and the Riemann problem cannot be solved by our techniques.

Given arbitrary points $\left(u_{l}, v_{l}\right)$ and $\left(u_{r}, v_{r}\right)$, a counterexample was given in [4] to show that the point $\left(u_{m}, v_{m}\right)$ in Theorem 4 may not exist even if (1) takes rather simple form. In [2] certain conditions on (1) were given to guarantee the existence of $\left(u_{m}, v_{m}\right)$. In the next theorem we prove that the solution to the Riemann problem is always unique.

TheOREM 5. Suppose that (3), (6) and (7) hold. Then there exists at most one solution to the Riemann problem $\left\{\left(u_{l}, v_{l}\right),\left(u_{r}, v_{r}\right)\right\}$ in the class of shocks, rarefaction waves and contact discontinuities which satisfies the entropy condition (E) across any discontinuity.

Proof. Suppose the Riemann problem $\left\{\left(u_{l}, v_{l}\right),\left(u_{r}, v_{r}\right)\right\}$ can be solved by connecting $\left(u_{l}, v_{l}\right)$ to $\left(u_{m}, v_{m}\right)$ by 1 -waves and $\left(u_{m}, v_{m}\right)$ to $\left(u_{r}, v_{r}\right)$ by 2 waves, and can also be solved by connecting $\left(u_{l}, v_{l}\right)$ to $\left(\bar{u}_{m}, \bar{v}_{m}\right)$ by 1 -waves and $\left(\bar{u}_{m}, \bar{v}_{m}\right)$ to $\left(u_{r}, v_{r}\right)$ by 2-waves (cf. Figure 2). By Theorem 3, $\left(u_{m}, v_{m}\right)$ and $\left(\bar{u}_{m}, \bar{v}_{m}\right)$ both belong to $\alpha_{1}\left(u_{l}, v_{l}\right) \cap \beta_{2}\left(u_{r}, v_{r}\right)$ and the proof of Theorem 5 will be complete if we can show that $\left(u_{m}, v_{m}\right)=\left(\bar{u}_{m}, \bar{v}_{m}\right)$. 

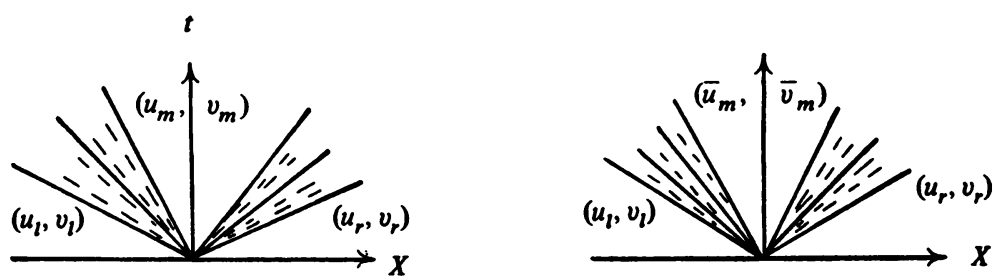

Figure 2

Suppose, $\left(u_{m}, v_{m}\right) \neq\left(\bar{u}_{m}, \bar{v}_{m}\right)$. By Theorem 4, we know $\left(u_{r}, v_{r}\right) \in$ $\alpha_{2}\left(u_{m}, v_{m}\right) \cap \alpha_{2}\left(\bar{u}_{m}, \bar{v}_{m}\right)$. Choose $\left(u^{1}, v^{1}\right)$ on $\alpha_{1}\left(u_{l}, v_{l}\right)$ between $\left(u_{m}, v_{m}\right)$ and $\left(\bar{u}_{m}, \bar{v}_{m}\right)$. Then by Lemma $1, \alpha_{2}\left(u^{1}, v^{1}\right)$ must intercept either $\alpha_{2}\left(u_{m}, v_{m}\right)$ or $\alpha_{2}\left(\bar{u}_{m}, \bar{v}_{m}\right)$ (cf. Figure 3), say at $\left(u_{1}, v_{1}\right)$.

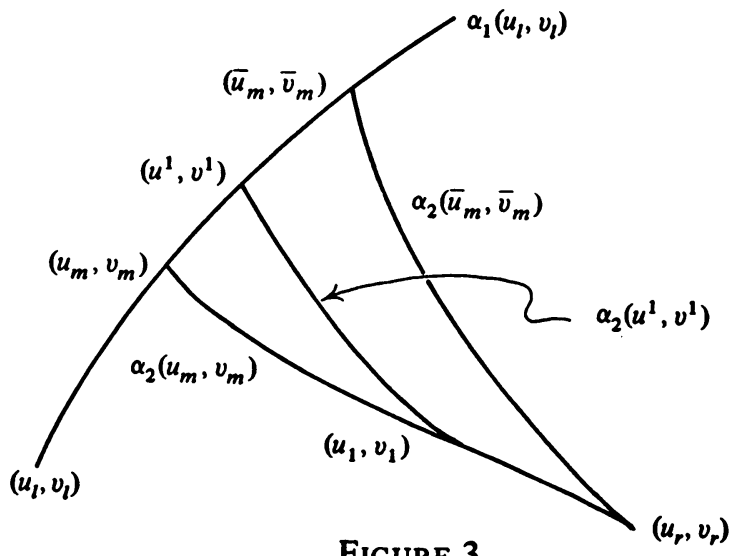

Figure 3

Without loss of generality, assume $\left(u_{1}, v_{1}\right) \in \alpha_{2}\left(u^{1}, v^{1}\right) \cap \alpha_{2}\left(u_{m}, v_{m}\right)$. It follows that both $\left(u_{m}, v_{m}\right)$ and $\left(u^{1}, v^{1}\right)$ belong to $\beta_{2}\left(u_{1}, v_{1}\right)$ by Theorem 3 . We then take $\left(u^{2}, v^{2}\right)$ on $\alpha_{1}\left(u_{l}, v_{l}\right)$ between $\left(u_{m}, v_{m}\right)$ and $\left(u^{1}, v^{1}\right)$. Again by Lemma $1, \alpha_{2}\left(u^{2}, v^{2}\right)$ must intercept either $\alpha_{2}\left(u^{1}, v^{1}\right)$ or $\alpha_{2}\left(u_{m}, v_{m}\right)$, say at $\left(u_{2}, v_{2}\right)$. Continuing the process, we get sequences $\left\{\left(u^{i}, v^{i}\right)\right\}$ and $\left\{\left(u_{i}, v_{i}\right)\right\}, i=$ $1,2, \ldots$, such that $\alpha_{2}\left(u^{i}, v^{i}\right)$ intercept either $\alpha_{2}\left(u^{i-1}, v^{i-1}\right)$ or $\alpha_{2}\left(u_{m}, v_{m}\right)$ at $\left(u_{i}, v_{i}\right)$. By our constructions, both sequences are contained in a bounded set and $\left\{\left(u^{i}, v^{i}\right)\right\}$ converges to a point, say $\left(u^{0}, v^{c}\right)$. Let $\left(u_{0}, v_{0}\right)$ be a limiting point of $\left\{\left(u_{i}, v_{i}\right)\right\}$. Since $\left(u^{i}, v^{i}\right)$ is in $\beta_{2}\left(u_{i}, v_{i}\right)$, we know that $\beta_{2}\left(u_{0}, v_{0}\right)$ is tangent to $\alpha_{1}\left(u_{l}, v_{l}\right)$ at $\left(u^{0}, v^{0}\right)$.

Suppose $\alpha_{1}\left(u_{l}, v_{l}\right)$ is composed of a shock or a mixed curve at $\left(u^{0}, v^{0}\right)$. Then there exists $\left(u^{*}, v^{*}\right)$ on $\alpha_{1}\left(u_{l}, v_{l}\right)$ such that $\left(u^{0}, v^{0}\right) \in S_{1}\left(u^{*}, v^{*}\right)$ and $h_{1}\left(u^{0}, v^{0} ; u^{*}, v^{*}\right)$ is a tangent to $\alpha_{1}\left(u_{l}, v_{l}\right)$ at $\left(u^{0}, v^{0}\right)$. Similarly, if $\beta_{2}\left(u_{0}, v_{0}\right)$ is composed of a shock or mixed curves at $\left(u^{0}, v^{0}\right)$, then there exists $\left(u_{*}, v_{*}\right)$ on $\beta_{2}\left(u_{0}, v_{0}\right)$ such that $\left(u^{0}, v^{0}\right) \in S_{2}\left(u_{*}, v_{*}\right)$ and $h_{2}\left(u_{*}, v_{*} ; u^{0}, v^{0}\right)$ is a tangent 
to $\beta_{2}\left(u_{0}, v_{0}\right)$ at $\left(u^{0}, v^{0}\right)$. Since $\beta_{2}\left(u_{0}, v_{0}\right)$ is tangent to $\alpha_{1}\left(u_{l}, v_{l}\right)$ at $\left(u^{0}, v^{0}\right)$, it follows that (cf. [2]).

(8) $\frac{g_{u}\left(u^{*}-u^{0}\right)+\left(\sigma_{1}-f_{u}\right)\left(v^{*}-v^{0}\right)}{f_{v}\left(v^{*}-v^{0}\right)+\left(\sigma_{1}-g_{v}\right)\left(u^{*}-u^{0}\right)}=\frac{g_{u}\left(u_{*}-u^{0}\right)+\left(\sigma_{2}-f_{u}\right)\left(v_{*}-v^{0}\right)}{f_{v}\left(v_{*}-v^{0}\right)+\left(\sigma_{2}-g_{v}\right)\left(u_{*}-u^{0}\right)}$ where $\sigma_{1}=\sigma\left(u^{*}, v^{*} ; u^{0}, v^{0}\right), \sigma_{2}=\sigma\left(u_{*}, v_{*} ; u^{0}, v^{0}\right)$, and $f_{u}, f_{v}, g_{u}, g_{v}$ are evaluated at $\left(u^{0}, v^{0}\right)$.

From (8), we have

$$
\left(v^{*}-v^{0}\right)\left(u_{*}-u^{0}\right)\left[f_{v} g_{u}-\left(\sigma_{1}-f_{u}\right)\left(\sigma_{2}-g_{v}\right)\right]
$$

$$
\begin{aligned}
& +\left(u^{*}-u^{0}\right)\left(u_{*}-u^{0}\right) g_{u}\left(\sigma_{1}-\sigma_{2}\right)+\left(v^{*}-v^{0}\right)\left(v_{*}-v^{0}\right) f_{v}\left(\sigma_{2}-\sigma_{1}\right) \\
& +\left(u^{*}-u^{0}\right)\left(v_{*}-v^{0}\right)\left[\left(\sigma_{1}-g_{v}\right)\left(\sigma_{2}-f_{u}\right)-f_{v} g_{u}\right]=0 .
\end{aligned}
$$

By Theorem 2, $\sigma_{2}>\sigma_{1}$ and so

$$
g_{u}\left(\sigma_{1}-\sigma_{2}\right)>0 \text { and } f_{v}\left(\sigma_{2}-\sigma_{1}\right)<0
$$

Since $\left\{\left(u^{*}, v^{*}\right) ;\left(u^{0}, v^{0}\right)\right\}$ and $\left\{\left(u^{0}, v^{0}\right) ;\left(u_{*}, v_{*}\right)\right\}$ both satisfy condition (E), we have, by Theorem 1 ,

$$
\lambda_{1}\left(u^{0}, v^{0}\right) \leqslant \sigma_{1}<\sigma_{2} \leqslant \lambda_{2}\left(u^{0}, v^{0}\right) .
$$

If $\sigma_{1}-g_{v} \geqslant 0$ and $\sigma_{2}-f_{u} \leqslant 0$, then

$$
\left(\sigma_{1}-g_{v}\right)\left(\sigma_{2}-f_{u}\right)-f_{v} g_{u}<0 \text {. }
$$

If $\sigma_{1}-g_{v}<0$, then $\left(\sigma_{1}-g_{v}\right)\left(\sigma_{2}-f_{u}\right)<\left(\sigma_{1}-g_{v}\right)\left(\sigma_{1}-f_{u}\right)+$ $\left(\sigma_{2}-\sigma_{1}\right)\left(\sigma_{1}-g_{v}\right)<\left(\sigma_{1}-g_{v}\right)\left(\sigma_{1}-f_{u}\right)$. On the other hand, since $\lambda_{1}$ and $\lambda_{2}$ are the two solutions of $\left(\lambda-f_{u}\right)\left(\lambda-g_{v}\right)-f_{v} g_{u}=0$, and $\lambda_{1} \leqslant \sigma_{1}<\lambda_{2}$, by (11), it follows that $\left(\sigma_{1}-g_{v}\right)\left(\sigma_{1}-f_{u}\right)-f_{v} g_{u} \leqslant 0$. Therefore $\left(\sigma_{1}-g_{v}\right)\left(\sigma_{2}-f_{u}\right)$ $-f_{v} g_{u}<0$ which is (12).

If $\sigma_{2}-f_{u}>0$, then $\left(\sigma_{1}-g_{v}\right)\left(\sigma_{2}-f_{u}\right)-f_{v} g_{u}<\left(\sigma_{2}-g_{v}\right)\left(\sigma_{2}-f_{u}\right)-$ $f_{v} g_{u}$ which is nonpositive, since $\lambda_{1}<\sigma_{2}<\lambda_{2}$.

We have proved that (12) holds in all cases. Similarly, using (11), we can prove that

$$
f_{v} g_{u}-\left(\sigma_{1}-f_{u}\right)\left(\sigma_{2}-g_{v}\right)>0 \text {. }
$$

Suppose that $\left(v^{*}-v^{0}\right)\left(u_{*}-u^{0}\right)>0$. Then $\left(u^{*}-u^{0}\right)\left(u_{*}-u^{0}\right)>0$, $\left(v^{*}-v^{0}\right)\left(v_{*}-v^{0}\right)<0$ and $\left(u^{*}-u^{0}\right)\left(v_{*}-v^{0}\right)<0$ because $\left(u^{0}, v^{0}\right) \in S_{1}\left(u^{*}, v^{*}\right)$ and $\left(u^{0}, v^{0}\right) \in S_{2}\left(u_{*}, v_{*}\right)$. Therefore by (10), (12) and (13), the left-hand side 
of $(9)$ is positive. This is a contradiction. Similarly, when $\left(v^{*}-v^{0}\right)\left(u_{*}-u^{0}\right)<$ 0 , then the left-hand side of $(9)$ is negative which is again a contradiction.

This completes the proof of the theorem when both $\alpha_{1}\left(u_{l}, v_{l}\right)$ and $\beta_{2}\left(u_{0}, v_{0}\right)$ are composed of shock or mixed curves at $\left(u^{0}, v^{0}\right)$. Analogously, the theorem is proved when either $\alpha_{1}\left(u_{l}, v_{l}\right)$ or $\beta_{2}\left(u_{0}, v_{0}\right)$ is composed of rarefaction curves at $\left(u^{0}, v^{0}\right)$. Q.E.D.

Finally, we remark that in [2] it was proved that (1) satisfies assumption (6) if

$$
f_{v}<0, \quad g_{u}<0, \quad f_{u} \geqslant 0 \text { and } g_{v} \leqslant 0
$$

(cf. [2, Lemma 1.2]). Therefore this paper extends the results of [2]. It can easily be proved that (1) also satisfies (6) if we take

$$
f_{v}<0 \text { and } g(u, v)=-u .
$$

This is an extention of the gas dynamics equations.

\section{REFERENCES}

1. P. D. Lax, Hyperbolic systems of conservation laws. II, Comm. Pure Appl. Math. 10 (1957), 537-566. MR 20 \#176.

2. T.-P. Liu, The Riemann problem for general $2 \times 2$ conservation laws, Trans. Amer. Math. Soc. 199 (1974), 89-112.

3. - The entropy condition and the admissibility of shocks, J. Math. Anal. Appl. (to appear).

4. J. A. Smoller, On the solution of the Riemann problem with general step data for an extended class of hyperbolic systems, Michigan Math. J. 16 (1969), 201-210. MR 40 \#552.

DEPARTMENT OF MATHEMATICS, UNIVERSITY OF MARYLAND, COLLEGE PARK, MARYLAND 20742 